UDC 123

LBC 87.159

\title{
FREEDOM AND INDEPENDENCE DURING THE PANDEMIC
}

\author{
Svetlana V. Dimitrova \\ Volgograd State University, Volgograd, Russian Federation \\ Kristina S. Ovdina \\ Volgograd State University, Volgograd, Russian Federation
}

\begin{abstract}
The scale and the speed of the spread of the new coronavirus strain and economic crises associated with it are becoming the reason to rethink the essential features and ways of interaction between freedom and independence. The aim of the research is to consider new and evaluate the significance of traditional approaches to defining independence and freedom. The authors analyze the mechanisms of the formation and development of biopower, the effectiveness of which is manifested in the possibility of turning people into "obedient bodies" (M. Foucault) and reducing human existence to the state of "bare life" (J. Agamben).The researchers emphasize that the highest form biopower manifestation, arose due to the effective development of medicine, became the possibility of transforming life and death into political concepts that require a "special solution". Therefore, the restrictive measures that arose during the spread of COVID-19 cannot be considered as a manifestation of total forms of addiction are established by biopolitics. The research allows the authors to come to the conclusion that the impossibility of achieving freedom and the loss of independence arise in the process of consistent implementation of the individualistic ideals. The results of the study contain a few contradictions identified by the authors. First of all, the development of biopower points that the concern for people's health enables the State to penetrate and manage all spheres of an individual's existence including issues of life and death. Biopolitics does not contribute to the establishment and development of civil rights, but creates effective means for reducing people to a state of "bare life". In the spread of COVID-19 the contradiction of following the individualistic ideals became obvious. Risks and threats that have a global character are confronted by a person unwilling to take responsibility. The revealed contradictions lead to the conclusion that a condition to maintain independence and achieve freedom in the modern world can be the formation of the new types of solidarities that make it possible to overcome the autonomy of existence and develop a responsible attitude to what is happening in the world.
\end{abstract}

Key words: freedom, independence, biopower, biopolitics, "bare life", individualism, solidarity.

Citation. Dimitrova S.V., Ovdina K.S. Freedom and Independence During the Pandemic. Logos et Praxis, 2021, vol. 20, no. 2, pp. 39-47. (in Russian). DOI: https://doi.org/10.15688/lp.jvolsu.2021.2.5

УДК 123

ББК 87.159

\section{СВОБОДА И НЕЗАВИСИМОСТЬ В ПЕРИОД ПАНДЕМИИ}

\author{
Светлана Васильевна Димитрова
}

Волгоградский государственный университет, г. Волгоград, Российская Федерация

\section{Кристина Сергеевна Овдина}

Волгоградский государственный университет, г. Волгоград, Российская Федерация

Аннотация. Масштабы и скорость распространения инфекции нового штамма коронавируса и связанных с ним экономических кризисов становятся основанием для переосмысления сущностных свойств и способов взаимодействия свободы и независимости. Целью исследования является рассмотрение новых и оценка значимости традиционных подходов к определению независимости и свободы. Проводится анализ 


\section{ИЗОЛЯЦИЯ В ОТКРЫТОМ ОБЩЕСТВЕ}

механизмов становления и развития биовласти, эффективность которой проявляется в возможности превращения людей в «послушные тела» (М. Фуко) и низведения бытия человека к состоянию «голой жизни» (Дж. Агамбен). Авторы подчеркивают, что высшей формой проявления биовласти, возникшей благодаря эффективному развитию медицины, явилась возможность превращения жизни и смерти в политические понятия, которые требуют «специального решения». В связи с этим ограничительные меры, возникшие в период распространения инфекции COVID-19, не могут быть рассмотрены как проявление тотальных форм зависимости, которые устанавливаются биополитикой. Логика исследования позволяет авторам прийти к выводу о том, что невозможность обретения свободы и потеря независимости возникают в процессе последовательной реализации идеалов индивидуализма. Выводами исследования стали выявленные авторами противоречия. Первое, касающееся развития биовласти, указывает на то, что забота о здоровье людей дает возможность государству проникать во все сферы существования индивида и управлять ими, включая вопросы жизни и смерти. Биополитика не способствует установлению и развитию гражданских прав, а создает эффективные средства для низведения людей к состоянию «голой жизни». В условиях распространения инфекции COVID-19 очевидным стало противоречие, сформированное в результате следования индивидуалистическим идеалам. Рискам и угрозам, обретающим глобальный характер, противостоит «скользящий по поверхности», не желающий брать на себя ответственность человек. Выявленные противоречия приводят к выводу о том, что условием сохранения независимости и обретения свободы в современном мире может стать формирование типов солидарностей, позволяющих преодолеть автономность существования и выработать ответственное отношение к происходящему в мире.

Ключевые слова: свобода, независимость, биовласть, биополитика, «голая жизнь», индивидуализм, солидарность.

Цитирование. Димитрова С. В., Овдина К. С. Свобода и независимость в период пандемии // Logos et Praxis. -2021. - T. 20, № 2. - C. 39-47. - DOI: https://doi.org/10.15688/lp.jvolsu.2021.2.5

Режим изоляции, карантинные меры, изменившие стиль и ритм жизни обществ, государств и отдельных людей, выступили основанием для переосмысления таких базовых понятий, как свобода, независимость, автономия. В условиях пандемии возникла «пограничная ситуация», приведшая к переоценке ценностей, а отношение к карантинным ограничениям поляризовало общество. С одной стороны, сформировалась позиция, согласно которой введенные ограничения являются необходимой мерой, улучшающей эпидемиологическую обстановку, с другой - возникла убежденность в том, что принятие новых форм контроля не обеспечивает безопасность, а лишь ограничивает свободу граждан.

Неправительственная организация «Freedom House», занимающаяся исследованиями политических и гражданских свобод, в своем докладе «Влияние COVID-19 на глобальную борьбу за свободу» утверждает, что пандемия спровоцировала кризис демократии во всем мире, а принятые правительствами меры в большинстве стран подорвали основные принципы демократии, создавая кризис глобальной свободы [Repucci, Slipowitz web].

Рассмотрим, какие формы зависимости возникли из-за ограничений, введенных в период пандемии.
Во-первых, ограничение свободы передвижения, которое в период локдауна касалось не только перемещения в другие страны и города, но распространялось на передвижения в местах проживания людей.

Во-вторых, значительно сузилась возможность свободного выбора и свободы действий людей. Выбор форм активности, реализующих как производственную деятельность, так и досуг, значительно сократился. Виды деятельности и формы отдыха людей стали строго регламентироваться государством.

В-третьих, появились новые способы контроля и риски при реализации прав, касающихся свободы слова и информации. Согласно отчету правозащитной организации «Freedom House», во время пандемии значительно снизился уровень свободы в интернете. По данным организации, «многие правительства намеренно используют карантин для ужесточения ограничений, к числу которых относится введение новых инструментов слежки за гражданами» [Shahbaz, Funk web].

Между тем современные IT-технологии сыграли важную роль в период пандемии, поскольку большинство видов социального взаимодействия и форм активности людей переходят в область виртуального. Самоизоляция, карантинные ограничения значительно усили- 
ли зависимость человека от информационнокоммуникационных технологий. Люди стали доверять технологиям все больше личной информации в условиях отсутствия необходимых конфиденциальных гарантий и законов. Таким образом, «отстаивание свободы интернета должно предусматривать меры по смягчению отрицательных побочных эффектов возросшей взаимосвязанности» [Морозов 2014, 327].

Так, особенность современной ситуации в том, что система ограничительных мер, включающая в себя свободу передвижения, изменение / ослабление социальных связей, межличностных форм коммуникаций, проблематизирует не только достижение свободы, но возможность независимого существования человека.

Актуальным становится определение сущностных различий свободы и независимости. Целью исследования является анализ новых и оценка значимости традиционных подходов к определению позитивной и негативной свободы. Амбивалентность свободы проявляется в том, что открытие новых путей освобождения неизменно сопровождается новыми видами зависимости.

Важными, находящимися в поле непосредственного восприятия, оказываются проблемы биополитики, биовласти. Понятие «биовласть» используется для описания степени зависимости, при которой подконтрольным объектом является тело человека. Расширение масштабов биополитических процессов (реализующих биовласть) проявляется и в установлении новых форм «социальной сегрегации и иерархизации», а также оказывается «действие на соответствующие силы тел и общностей, обеспечивая отношения господства и эффекты гегемонии» [Фуко 1996, 246].

Актуальным является тезис М. Фуко о единстве процессов, направленных на борьбу с эпидемией и создающих условия для формирования дисциплинированного общества. Автор работы «Надзирать и наказывать. Рождение тюрьмы» отмечает, что «чума - не общий праздник, а строгие границы; не нарушение законов, а проникновение правил даже в мельчайшие детали повседневной жизни посредством совершенной иерархии, обеспечивающей капиллярное функционирование власти; не надеваемые и сбрасываемые маски, а присвоение каждому индивиду его “истинного” имени, “истинного” места, “истинного" тела и “истинной” болезни» [Фуко 2020, 241].

Однако в ходе исследования властных отношений М. Фуко представил зарождение и развитие новой формы власти - «биовласти». «Дисциплинирующая власть управляет множеством для того, чтобы превратить его в послушные тела и заставить участвовать в общественных процессах с целью получения экономической выгоды. Биополитическая технология обращается к множественности именно потому, что оно уже участвует в общих глобальных процессах: рождение, воспроизводство, болезни, смерть и т. д.» [Самовольнова 2017, 262].

Усиление контроля биовласти связано с разработкой и применением специализированных методов исследования человеческого организма, квалифицированных практик, направленных на сохранение здоровья людей и делающих подконтрольными такие процессы, как рождаемость и продолжительность жизни. Эффективные высококвалифицированные действия предоставляют возможность власти проникать во все формы жизни человека, включая биологическую.

Современный итальянский исследователь, профессор Венецианского университета Дж. Агамбен, развивая идеи М. Фуко, утверждает, что при определении механизмов становления и масштабов воздействия биовласти необходимо «проанализировать отношение, которое связывает друг с другом голую жизнь и суверенную власть» [Агамбен 2011, 88]. Понятие «голая жизнь» вводится итальянским философом для того, чтобы показать, как власть устанавливает границу между правовым и естественным / биологическим существованием человека.

Важно отметить, что естественное состояние - это понятие, которое широко использовалось мыслителями XVII-XVIII веков. Несмотря на различие подходов к определению естественного состояния, философы утверждали, что общественный договор необходим, поскольку он (договор) способствует установлению гражданской формы существования людей. Если у Т. Гоббса государственная власть должна была преодолеть естественное состояние - «войну всех против всех», то, 
согласно учению Дж. Локка, переход к общественному состоянию предполагает заключение политического соглашения, при котором сохранятся главные характеристики естественного закона - это равенство и свобода. Ведь закон природы «требует мира и сохранения всего человечества» [Локк 1988, 265].

Таким образом, установление власти государства выступает условием перехода к гражданской форме жизни. Заключение общественного договора предполагает, что граждане принимают на себя обязательства в обмен на сохранение жизни и частной собственности.

Парадокс заключается в том, что современный уровень развития цивилизации выступает условием для того, чтобы «вернуть» людей не просто к естественному состоянию, а низвести их к «голой жизни». Отличие «естественного состояния» от «голой жизни» заключается в том, что человек не возвращается к следованию законам природы, а по воле государства оказывается в положении, при котором даже вопрос о жизни и смерти решается правительством.

В состоянии «голой жизни» оказываются беженцы, узники концлагерей, а одним из механизмов лишения гражданских прав и низведения людей до состояния «голой жизни» является введение чрезвычайного положения. «Голая жизнь, в которую превратились заключенные лагерей, тем не менее не является естественным фактом, внеположным политике, который право способно лишь удостоверить или признать; скорее в нашем анализе это рубеж, где право всякий раз переходит в реальность, а реальность - в право и где два этих плана стремятся к неразличимости», отмечает Дж. Агамбен [Агамбен 2011, 217].

Полная приостановка действий права, которую Дж. Агамбен определяет как «чрезвычайноеположение», лишает людей гражданских прав, распространяя власть государства даже на решение вопроса о жизни и смерти. Таким образом, человек оказывается «лишенным символической “одежды” защищающих его (прикрывающих его естественную “наготу") законов. Именно на этом пределе и обнаруживается чисто биологическое существование человека, которое больше ничего не стоит, а значит может быть уничтожено без вины и ответственности. Символическое "стирание" предваряет физическое уничтожение человека» [Яркеев 2020, 55].

Следовательно, сущностные черты биовласти проявляются в том, что, основываясь на научных исследованиях, высококвалифицированных действиях, власть «может определять тот момент, в который жизнь перестает быть политически значимой» [Агамбен 2011, 181].

Режим самоизоляции, атомизация общества, которые сопровождаются усилением контроля и увеличением степени проникновения в жизнь людей, сформировали новый стиль поведения, одобренный экспертами и санкционированный государством. Однако возникшая в современных условиях беспрецедентная ситуация, характеристиками которой являются высокая скорость и мировые масштабы распространения инфекции, не является, на наш взгляд, качественно новой формой проявления биовласти.

Успешное развитие медицины уже привело к подвижности экзистенциальных границ. Констатация смерти не основывается только на объективных биологических показателях, а является еще и результатом соглашения медиков, юристов, религиозных деятелей и т. д.

Дж. Агамбен отмечает: «На наших глазах разворачивается всеохватывающий процесс, ставкой в котором является именно перекройка этих границ - и именно сейчас становится совершенно очевидным, что суверенная власть осуществляется лишь поддержанием границ, заново срастаясь с медицинским и биологическим знанием» [Агамбен 2011, 258].

Тело национализируется, проблема определения границ жизни и смерти становится биополитической, «сегодня жизнь и смерть являются не собственно научными понятиями, но понятиями политическими, которые в силу своей политической природы приобретают точное значение лишь в результате специального решения» [Агамбен 2011, 208].

Между тем следует обратить внимание и на то, что биовласть тесно связана с идеалами индивидуалисткой этики. По сути, задача биополитики заключается в том, чтобы индивид сосредоточил все внимание на самом 
себе, собственном теле. Показательным является то, что забота о здоровье индивида, мероприятия, направленные на регулирование роста рождаемости и создание условий для увеличения продолжительности жизни людей, являются механизмами биополитики. «Право верховной власти суверена заставить человека умереть или позволить ему жить сменилось правом заставить индивида жить или позволить ему умереть» [Самовольнова 2017, 262]. Таким образом, последовательное движение к идеалам индивидуализма приводит к видам зависимости, которые поддерживаются биполитикой.

Отметим, что стремительное распространение инфекции и связанные с ним ограничения позволили прийти к пониманию о том, что следование идеалам индивидуализма не только не позволяет человеку обрести свободу, но и лишает независимости. Таким образом, возникшая «пограничная ситуация», на наш взгляд, сделала более явной ограниченность идеалов индивидуализма, следование которым является в настоящий момент угрозой выживанию, а высокая степень рискогенности современных обществ, глобальный характер угроз и опасностей становятся основанием для преодоления ценностей индивидуализма.

Важно отметить, что идеалы индивидуализма эпохи модерн уже были подвергнуты критике в учениях постмодернистов. Вместе с тем анализ новых форм проявления индивидуализма - «гипериндивидуализма» 3. Баумана - «гиперпотребительства» Ж. Липовецки позволяют нам указать на особенность современной ситуации, которая заключается в том, что индивидуалистская этика сегодня выступает основанием не только кризиса идентификации, но и снижает способность человечества противостоять глобальным рискам и угрозам.

Между тем постмодернисты указывают на то, что в условиях существования изменчивого, гибкого, непредсказуемого мира возникают новые формы проявления индивидуализма. 3. Бауман в работе «Индивидуализированное общество» пишет, что «ненадежность, нестабильность, уязвимость - стали широко распространенными (и наиболее болезненно ощущаемыми) чертами современ- ной жизни» [Бауман 2002, 154]. Определение перспектив развития связано с тем, что «впереди нас ждет лишь большая гибкость, большая рискованность и большая уязвимость» [Бауман 2002, 117]. При этом «неопределенность и мягкость» мира оказывает влияние на формы активности людей, этические идеалы, способы самоопределения.

Постоянный поиск идентичности является неожиданным и побочным продуктом глобализации. Проблема заключается в «незавершенности» идентичности, которая становится бременем для современного человека, так как «тяжесть "незавершенности" идентичности многократно усиливает индивидуальную ответственность за ее завершение» [Бауман 2002, 118].

Человек в глобализированном мире теряет свое статичное состояние, а его положение становится «неустроенным», иными словами, индивид в условиях современной реальности не имеет гарантированного сохранения стабильности ни в одной из сфер его жизни. Устойчивая идентичность сменяется пребыванием в ситуации постоянного выбо$\mathrm{pa} /$ изменения.

3. Бауман утверждает, что жизнь людей превратилась в череду сменяющихся эпизодов, которые никак не связаны между собой. Это проявляется в том, что люди вынуждены часто менять профессию и, соответственно, они овладевают навыками, которые могут быть использованы «здесь и сейчас». Независимому индивиду эпохи модерна, имеющему стабильный заработок, стремящемуся быть конкурентоспособным, совершенствующему свои профессиональные навыки, противостоит индивид, часто меняющий форму деятельности, имеющий временные заработки, сводящий контакты с другими людьми к исполнению пунктов контракта. «Фрагментация жизни, - пишет 3. Бауман, - приводит к тому, что люди живут эпизодами, при этом жизнь превращается в серию не связанных между собой событий. Ощущение небезопасности это такой рубеж, когда бытие распадается на фрагменты, а жизнь - на эпизоды» [Бауман 2002, 160].

В соответствии с проживаемыми жизненными эпизодами человек получает возможность просто выбрать / поменять соб- 
ственную идентичность. Таким образом, современный человек становится воплощением фрагментарности, мобильности, гипериндивидуализма. Его жизнь теряет свою фиксированность и приобретает «текучий», постоянно движущийся характер.

Поскольку жизнь людей, поиск идентичности и способы достижения свободы кардинально меняются, то появляется необходимость в формировании новых концептов и теорий, описывающих современную картину мира и положение человека в ней. Еще в 19701980-х гг. Ж. Бодрийяр ввел термины с приставкой «гипер-». Французский философ в своей знаменитой работе «Симулякры и симуляция» вводит ключевой термин, характеризующий современность, - «Гиперреальность». Этот термин, провозглашающий начало эры симуляции, используется для указания на сокрытие того, что реальное перестало быть таковым. «Отныне гиперреальное экранировано от воображаемого и от какого-либо различения между реальным и воображаемым, оставляя место лишь орбитальному самовоспроизведению моделей и симулированному порождению различий» [Бодрийяр 2016, 7].

Новые подходы к пониманию свободы и независимости в эру симуляции очень разнообразны, один из них представлен в учении Ж. Липовецки, в котором «гипермодернизм» связан прежде всего с культурой изобилия и избытка. В работе «Эра пустоты. Эссе о современном индивидуализме» автор указывает на произошедший переворот, трансформацию ценностей, повлекшие за собой преобразование дискурсов и изменившие образ жизни людей. Ж. Липовецки отмечает, что «на смену дисциплинарному и воинствующему индивидуализму пришел индивидуализм на выбор - гедонистический и психологический, считающий главной целью личные достижения человека... исторический разрыв с неоиндивидуализмом означал еще большее усиление тяги к самостоятельности со стороны индивидов независимо от их социальной принадлежности и пола» [Липовецки 2001, 318].

Преодоление «дисциплинарной социализации» призвано способствовать установлению индивидуальной свободы, которая проявляется в поощрении индивидуальных потребностей и ориентированности социальных ин- ститутов только на мотивации и желания человека. «Жить свободно, не подвергаясь принуждениям, от начала и до конца выбирать свой способ существования - никакой другой факт общественной и культурной жизни не является более значительным событием в глазах современников», - отмечает Ж. Липовецки [Липовецки 2001, 21].

В условиях формирования новой стадии индивидуализма возникает тип личности, характерной чертой которого становится повышенное внимание к собственному телу. Нарцисс, интересы которого сосредоточены на «собственной самобытности», на красоте и желаниях своего тела, становится главным символом современности. Путь к свободе предполагает «бесконечную работу по освобождению, наблюдению и объяснению своей личности» [Липовецки 2001, 86].

Весьма парадоксально рассмотрена концепция свободы в работах американского социального теоретика Р. Сэмюэлса, который анализирует соотношение автономии / свободы и автоматизации. Разработчик концепции автомодернизма справедливо отмечает, что для понимания соотношения понятий свободы и независимости необходимо учитывать роль и степень влияния цифровых технологий на жизнь человека. А.В. Павлов, анализируя основные положения новой постпостмодернистской теории, отмечает, что в автомодернизме «высокий уровень автоматизации сочетается с усиленным желанием получить / завоевать личную автономию... по большему счету мы наблюдаем сегодня рождение новой культурной и социальной субъектности» [Павлов 2019, 447-448].

Современные технологии, социальные сети (которые стали востребованы еще в большей степени в период пандемии) дают человеку безграничные возможности для расширения и усиления индивидуализма. Современный человек любит проводить время в виртуальном пространстве, обновляя свои профили в социальных сетях, добавляя все больше и больше новой информации о себе, тем самым проявляя свой индивидуализм. Последний также имеет выражение в «эгокастинге», то есть в потреблении только той информации, которая соответствует собственному мировоззрению. Сэмюэлс говорит о том, что «современ- 
ность указывает на доминирование науки, разума, равенства, индивидуализма, терпимости, но также преобладания безличности, отчуждения, сегрегации, колонизации и социального конформизма» [Samuels 2009, 8]. Цифровые технологии становятся парадоксальным местом, где, с одной стороны, человек стремиться проявить свой индивидуализм, но с другой - попадает в рамки социального конформизма.

По мнению Сэмюэлса, данные технологии придают человеку ощущение автономии и контроля над происходящим, хотя это чувство может носить иллюзорный характер. Исследователь утверждает, что человек, ведя свой собственный блог или играя в игру, ощущает, что имеет полный контроль над происходящим, но на самом деле он действует всего лишь в рамках заготовленных шаблонов. Иллюзорность таким образом понимаемой свободы становится очевидной при столкновении индивида с глобальными рисками, к числу которых относится и распространение COVID-19.

Индивидуальная свобода в «автомодерне» - это «свобода от...». «Свобода не думать или не взаимодействовать в социальных отношениях - это высоко ценимая свобода в данном культурном порядке. Аналогичным образом автомодернистское провозглашение свободы слова частично обусловлено стремлением освободиться от социальных, политических, межличностных и традиционных ограничений» [Samuels 2007, 236].

Таким образом, следование идеалам индивидуализма в эпоху модерна давало ощущение независимого существования немногим людям, вытесняя «на обочину» все более разнообразные группы (люди другой расы, мигранты, женщины и т. д.). В то же время гипериндивидуализм сделал наиболее значимым то, что раньше относилось к маргинальному поведению - исключение оседлости, «скольжение по поверхности», выражающееся как в непрерывном перемещении, поисках новых впечатлений, типов наслаждений, так и в отсутствии каких-либо форм ответственности.

Единственной заботой человека эпохи постмодерна становится обеспечение личной безопасности. Однако в условиях современ- ного мира возникающие угрозы и риски могут сделать физически невозможным «скользящего по поверхности» человека. Так, наиболее последовательная реализация идеалов индивидуализма ясно показывает, что для сохранения жизни, независимости и создания условий для обретения свободы необходимо формировать чувство личной ответственности, которое станет основанием для возникновения новых форм солидарности.

Делая выводы, укажем на то, что в современном мире сформировался и достиг в наивысшей степени проявления ряд противоречий.

Первое из них связано с тем, что забота о жизни и здоровье человека неизменно предполагает расширение биовласти, создающей возможности оказывать воздействие / господствовать над телом человека. Наивысшая степень проявления биовласти заключается в том, что современная медицина позволила расширить экзистенциальные границы, сделав решение вопроса о жизни и смерти человека результатом принятых конвенций профессиональных групп и властных структур.

Второе противоречие проявляется в том, что даже первичный анализ возникающего опыта борьбы с распространением инфекции COVID-19 со всей очев идностью показал, что условием безопасности являются различные формы проявления гражданской активности, неинституализированные типы солидарности. Вместе с тем особенность современного гибкого, изменяющегося мира заключается в том, что человек, приспосабливаясь к постоянно изменяющейся действительности, следует идеалам «гипериндивидуализма» и не находит оснований для формирования солидарности.

Третьим противоречием, которое может служить выводом нашего исследования, является указание на то, что распространение глобальных рисков и угроз выступит основанием для формирования социального порядка, фундированного такими типами солидарности, которые основаны на общечеловеческих ценностях.

\section{СПИСОК ЛИТЕРАТУРЫ}

Агамбен 2011 - Агамбен Дж. Ноmo sacer. Суверенная власть и голая жизнь. М.: Европа, 2011. 
Бауман 2002 - Бауман 3. Индивидуализированное общество. М.: Логос, 2002.

Бодрийяр 2016 - Бодрийяр Ж. Симулякры и симуляции. М.: ПОСТУМ, 2016.

Липовецки 2001 - Липовецкки Ж. Эра пустоты. Эссе о современном индивидуализме. СПб.: Владимир Даль, 2001.

Локк 1988-Локк Дж. Два трактата оправлении // Сочинения. В 3 т. Т. 3. М.: Мысль, 1988. С. 135-405.

Морозов 2014 - Морозов Е. Интернет как иллюзия. Обратная сторона сети. М.: ACT: CORPUS, 2014.

Павлов 2019 - Павлов А.В. Постпостмодернизм: как социальная и культурная теории объясняют наше время. М.: Дело, 2019.

Самовольнова 2017 - Самовольнова О.В. Социально-философский анализ основных концепций биополитики: М. Фуко, Дж. Агамбен, А. Негри // Вестник РГГУ. Серия: Философия. Социология. Искусствоведение. 2017. № 4 (10), ч. 2. C. 261-271.

Фуко 1996 - Фуко М. Воля к истине: по ту сторону знания, власти и сексуальности. Работы разных лет. М.: Каталь, 1996.

Фуко 2020 - Фуко М. Надзирать и наказывать. Рождение тюрьмы. М.: Ад Маргинем Пресс: Музей современного искусства «Гараж», 2020.

Яркеев 2020 - Яркеев А.В. Концепция биополитики и ее генеалогия // Дискурс-Пи. 2020. № 1 (38). C. 50-59.

Repucci, Slipowitz web-Repucci S., Slipowitz A. Democracy After Lockdown. The Impact of COVID-19 on the Global Struggle for Freedom // https://freedomhouse.org/report/specialreport/2020/democracy-under-lockdown.

Shahbaz, Funk web - Shahbaz A., Funk A. Freedom on Net 2020. The Pandemics Digital Shadow // https://freedomhouse.org/report/freedomnet/2020/pandemics-digital-shadow.

Samuels 2007 - Samuels R. Automodernism. Automodernity after Postmodernism: Autonomy and Automation in Culture, Technology, and Education // McPherson T. (ed.) Digital Youth, Innovation, and the Unexpected. Cambridge (MA): The MIT Press, 2007. P. 219-240.

Samuels 2009-Samuels R. New Media, Cultural Studies, and Critical Theory after Postmodernism. Automodernity from Zizek to Laclau. N. Y.: Palgrave Macmillan, 2009.

\section{REFERENCES}

Agamben G., 2011. Homo Sacer. Sovereign Power and Naked Life. Moscow, Evropa Publ.

Bauman Z., 2002. Individualized Society. Moscow, Logos Publ.

Baudrillard J., 2016. Simulacra and Simulation. Moscow, POSTUM Publ.

Lipovetsky G., 2001. The Era of Emptiness. Essays on Contemporary Individualism. Saint Petersburg, Vladimir Dal Publ.

Locke J., 1988. Two Treatises on Government. Essays. In 3 vols. Vol. 3. Moscow, Mysl' Publ.

Morozov E., 2014. The Net Delusion. The Dark Side of Internet Freedom. Moscow, AST Publ., CORPUS Publ.

Pavlov A.V., 2019. Post-Postmodernism: How Social and Cultural Theories About "Clarify Our Time. Moscow, Delo Publ.

Samovol'nova O.V., 2017. Socio-Philosophical Analysis of the Basic Concepts ofBiopolitics: M. Foucault, J. Agamben, A. Negri. Vestnik RGGU. Seriya: Filosofiya. Sociologiya. Iskusstvovedenie, no. 4(10), pt. 2, pp. 261-271.

Foucault M., 1996. The Will to Knowledge. Works of Different Years. Moscow, Katal' Publ.

Foucault M., 2020. Discipline and Punish. The Birth of the Prison. Moscow, Ad Marginem Press, Muzej sovremennogo iskusstva «Garazh».

Yarkeev A.V., 2020. The Concept of Biopolitics and its Genealogy. Diskurs-Pi, no. 1 (38), pp. 50-59.

Repucci S., Slipowitz A. Democracy After Lockdown. The Impact of COVID-19 on the Global Struggle for Freedom. URL: https://freedomhouse.org/ report/special-report/2020/democracy-underlockdown.

Shahbaz A., Funk A. Freedom on Net 2020. The Pandemics Digital Shadow. URL: https:// freedomhouse.org/report/freedom-net/2020/ pandemics-digital-shadow.

Samuels R., 2007. Automodernism. Auto-Modernity after Postmodernism: Autonomy and Automation in Culture, Technology, and Education. Digital Youth, Innovation, and the Unexpected. Cambridge (MA), The MIT Press, pp. 219-240.

Samuels R., 2009. New Media, Cultural Studies, and Critical Theory After Postmodernism. Automodernity from Zizek to Laclau. New York, Palgrave Macmillan. 


\section{Information About the Authors}

Svetlana V. Dimitrova, Doctor of Sciences (Philosophy), Professor, Department of Philosophy, Volgograd State University, Prosp. Universitetsky, 100, 400062 Volgograd, Russian Federation, sve-dimitrova@yandex.ru, https://orcid.org/0000-0003-4962-0692

Kristina S. Ovdina, Applicant, Department of Philosophy, Volgograd State University, Prosp. Universitetsky, 100, 400062 Volgograd, Russian Federation, ovdinakristina@inbox.ru, https://orcid.org/0000-0002-4281-7620

\section{Информация об авторах}

Светлана Васильевна Димитрова, доктор философских наук, профессор кафедры философии, Волгоградский государственный университет, просп. Университетский, 100, 400062 г. Волгоград, Российская Федерация, sve-dimitrova@yandex.ru, https://orcid.org/0000-0003-4962-0692

Кристина Сергеевна Овдина, соискатель кафедры философии, Волгоградский государственный университет, просп. Университетский, 100, 400062 г. Волгоград, Российская Федерация, ovdinakristina@inbox.ru, https://orcid.org/0000-0002-4281-7620 